\title{
IgG enzyme linked immunosorbent assay for diagnosis of invasive aspergillosis: retrospective study over 15 years of transplant recipients
}

\author{
AK TRULL, J PARKER, RE WARREN \\ From the Clinical Microbiology and Public Health Laboratories, Addenbrooke's Hospital, Cambridge
}

SUMMARY Four commercially available Aspergillus fumigatus antigens were compared in an IgG enzyme linked immunosorbent assay by testing multiple sera from 19 patients who had received renal and hepatic allografts and who had histologically confirmed invasive aspergillosis. Raised antibody levels were found in 16 of the 19 patients. More antibody responses were detected by culture filtrate antigens, but somatic antigens often detected antibodies sooner. When antibodies to Aspergillus antigens were present before transplantation the onset of fatal disseminated infection was earlier. Antibody levels often fell to within the normal range, even in cases of fulminant disseminated infection. Repeated serology was essential for detection of an antibody response.

In many countries invasive aspergillosis is the second most prevalent opportunistic mycosis in man. Its incidence is greater in patients whose immunity has been compromised by cytotoxic chemotherapy or immunosuppression after transplantation.' ${ }^{1}$ The onset of invasive aspergillosis may be insidious or acute, and the infection can be complicated by concurrent infections and be rapidly fatal. Diagnosis may be delayed because Aspergillus is rarely cultured from specimens before death and the importance of isolating this organism from sputum is often doubted. Biopsies of a localised lesion may show invasive aspergillosis but may be impractical owing to the patient's underlying condition.

Early diagnosis is important if the immunocompromised patient is to be successfully treated. ${ }^{2}$ Detection of antibodies to Aspergillus might confirm or suggest invasive aspergillosis in immunocompromised patients, with or without isolation of the organism from sputum. Various serological methods have been assessed for the diagnosis of invasive aspergillosis. Immunoprecipitation has yielded variable and sometimes disappointing results. ${ }^{3-7}$ In one series only five of 19 patients were positive by immunodiffusion and four by countercurrent immunoelectrophoresis. ${ }^{8}$ By contrast, raised protein A binding antibodies to Aspergillus antigens were detected by radiobinding assay in 15 of 19 patients with invasive aspergillosis seven or more days after

Accepted for publication 13 May 1985 the onset of infection. Others have found enzyme linked immunosorbent assay to be more sensitive than immunodiffusion and countercurrent immunoelectrophoresis in cases of allergic bronchopulmonary aspergillosis and invasive aspergillosis. ${ }^{9}$

Various antigenic extracts of Aspergillus fumigatus are commercially available, but they have not been compared for their value in the early diagnosis of invasive aspergillosis. A retrospective longitudinal study of patients with invasive aspergillosis who had undergone transplantation was designed to evaluate four commercial antigens in an Aspergillus IgG enzyme linked immunosorbent assay.

\section{Material and methods}

Nineteen patients (15 with a renal allograft, four with an hepatic allograft) with histological evidence of invasive aspergillosis were selected because serial serum samples had been prospectively collected between 1968 and 1983 and stored at $-20^{\circ} \mathrm{C}$ (Public Health Laboratory, Addenbrooke's Hospital).

In 14 of the 19 cases histological evidence of disseminated aspergillosis (invasive aspergillosis outside the respiratory tract) was obtained from necropsy material (nine patients) or biopsy (four), or both (one). A fumigatus was isolated from sputum cultures or bronchial washings before death in seven of these 14 patients, all with disseminated infection. 
One patient was successfully treated for disseminated disease and survived. Of the five patients with invasive aspergillosis apparently confined to the respiratory tract, none had evidence of aspergillosis from either sputum culture or biopsy during life. In 12 of the 19 cases (10 cases of disseminated infection) $\boldsymbol{A}$ fumigatus was cultured from specimens of tissue before or after death, or both. A total of 128 serum specimens, including preoperative samples from 11 patients, were available for testing. Samples were chosen at times coinciding with changes in the patient's clinical condition or, especially in later transplantations, with the isolation of Aspergillus from sputum or biopsy specimens.

Single serum samples were collected from 71 unselected patients who had undergone cardiac transplantation before the operation and from 134 unselected patients with haematological malignancy attending outpatient clinics. Eight sera from patients with aspergillomas who had not undergone transplatation and were found to be precipitin positive by countercurrent immunoelectrophoresis, together with sera from nine pregnant women negative for precipitins (originally obtained for rubella serology), were used for checkerboard titrations and to standardise the Aspergillus IgG enzyme linked immunosorbent assay.

\section{ASPERGILLUS FUMIGATUS ANTIGENS}

Somatic (Mercia Brocades, Lot 136; Bencard No 1, Lot S2112) and culture filtrate (Mercia Brocades, Lot 136; Bencard No 2, Lot S1964) antigens were used in both the IgG enzyme linked immunosorbent assay and the countercurrent immunoelectrophoresis. A single batch of each of the four antigens was used throughout the study.

COUNTERCURRENT IMMUNOELECTROPHORESIS Precipitating antibodies to the commercial $A$ fumigatus antigens $(20 \mathrm{mg} / \mathrm{ml})$ were detected in serum by countercurrent immunoelectrophoresis with the use of $20 \mathrm{mM}$ barbitone buffer ( $\mathrm{pH} \mathrm{8.6)}$ and $1 \%(w / v)$ agarose (Litex-LSA) as previously described. ${ }^{10}$ Non-specific precipitation was eliminated by washing the gel in $5 \%(\mathrm{w} / \mathrm{v})$ trisodium citrate.

\section{ASPERGILLUS IgG ENZYME LINKED}

\section{IMMUNOSORBENT ASSA Y}

Checkerboard analysis Two checkerboard titrations were carried out to determine the optimum assay conditions for each of the four antigens used. In the first checkerboard two serum samples from the control patients with pulmonary aspergilloma were chosen, one of which formed multiple precipitin lines and the other few. These were compared with a single precipitin negative serum. Antigen, test serum, and enzyme conjugate concentrations were varied, and a narrower range of antigen and serum dilutions was selected to provide good discrimination between precipitin positive and negative sera. The optimum dilution of conjugate for development of colour within 20-40 minutes was determined.

In the second checkerboard eight precipitin positive sera were compared with eight precipitin negative sera. Concentrations of antigen and test serum were varied within the narrower ranges established in the first checkerboard. Student' $s t$ test was applied to determine the best conditions for discriminating between precipitin positive and negative sera.

Enzyme linked immunosorbent assay method Antigen at the optimum concentration $(10-40 \mu \mathrm{g} / \mathrm{ml})$ in $100 \mu \mathrm{l}$ volumes $0.05 / \mathrm{M}$ carbonate/bicarbonate buffer ( $\mathrm{pH} \mathrm{9.6)} \mathrm{was} \mathrm{incubated} \mathrm{overnight} \mathrm{at} 37^{\circ} \mathrm{C}$ in the inner wells of flexible polyvinyl microtitre plates (Cooke, Dynatech 1-220-229). After washing three times in phosphate buffered saline $(\mathrm{pH} \mathrm{7.3)} 0 \cdot 15 \mathrm{M}$ supplemented with $0.05 \%(\mathrm{v} / \mathrm{v})$ Tween 20 (phosphate buffered saline/Tween) $100 \mu$ l volumes of the test and control sera were added in duplicate to the wells at the optimum dilution (1:100 or 1:500) in phosphate buffered saline/Tween 20 supplemented with $1 \%(\mathrm{w} / \mathrm{v})$ bovine serum albumin (assay buffer).

After incubation for two hours at $37^{\circ} \mathrm{C}$ and wash ing binding antibody was detected with goat antihuman IgG conjugated with alkaline phosphatase (Miles Yeda) at the optimum dilution (1:500 or 1:1000) in assay buffer. After incubation for three hours at $37^{\circ} \mathrm{C}$ and washing enzyme substrate (Sigma $104-105)$ at $1 \mathrm{mg} / \mathrm{ml}$ diethanolamine buffer ( $\mathrm{pH}$ 9.6) was added and the colour developed for 20-40 minutes until the optical density of a previously selected positive control serum at a 1:100 dilution reached a value of 1.9-2.0. The reaction was then stopped with $3 / \mathrm{M}$ sodium hydroxide and the optical density of test and control samples measured spectrophotometrically at $405 \mathrm{~nm}$.

Standardisation of enzyme linked immunosorbent assay A single positive (standard) serum from a control patient with aspergilloma was included in every assay at a range of seven dilutions between $1: 100$ and $1: 10000$ in assay buffer. The enzyme linked immunosorbent assay optical density reading for each dilution was plotted against the serum dilution to provide a standard curve. The optical density reading for each test sample was read off this standard curve and expressed in arbitrary units of antibody on a logarithmic scale. One hundred units of antibody were equated to a $1: 100$ dilution of the standard serum.

The same eight negative control sera as were used for checkerboard analysis plus one additional pre- 
cipitin negative normal control serum sample were also included in every assay performed. The mean plus two standard deviations of IgG antibody units of these nine negative controls was calculated for each antigen examined and assigned a value of 1.0. In all assays of test sera units of antibody were related to this value in terms of a ratio, giving an antibody index. An antibody index of 1.0 for any antigen represented the upper limit of the normal range of IgG antibodies to Aspergillus. Values above 1.0 were considered to be significantly raised.

Fungal specificity of enzyme linked immunosorbent assay The specificity of the enzyme linked immunosorbent assay for IgG antibodies to Aspergillus was assessed by absorbing a serum sample that was precipitin negative but strongly positive in the enzyme linked immunosorbent assay with different antigens. Replicate absorptions of the serum diluted $1: 100$ in assay buffer were performed with Candida albicans whole cell extract (Mercia Brocades) and Aspergillus somatic and culture filtrate antigens at six concentrations, from $1000 \mu \mathrm{g} / \mathrm{ml}$ in 10 -fold dilutions down to $0.01 \mu \mathrm{g} / \mathrm{ml}$. All tubes were incubated overnight at $4^{\circ} \mathrm{C}$ and then the sera retested in the enzyme linked immunosorbent assay.

\section{Results}

\section{ASPERGILLUS IgG ENZYME LINKED}

IMMUNOSORBENT ASSAY SPECIFICITY

Discrimination between the eight precipitin positive and eight precipitin negative sera was obtained under optimum conditions for the enzyme linked immunosorbent assay for all four commercial antigens tested ( $p \ll 0.001$, data not shown). IgG antibodies to Aspergillus were absorbed completely by both Aspergillus somatic and culture filtrate antigens at $100 \mu \mathrm{g} / \mathrm{ml}$. Absorption with Candida antigens at 10 times this concentration failed to reduce antibody binding appreciably. The enzyme linked immunosorbent assay had a lower detection limit of $100 \mathrm{ng} / \mathrm{ml}$ affinity purified IgG antibodies to Aspergillus cell wall antigens (data not shown).

\section{RENAL AND HEPATIC TRANSPLANT RECIPIENTS} WITH INVASIVE ASPERGILLOSIS

Sixteen of the 19 patients had one or more serum samples positive against one or more antigens in the Aspergillus IgG enzyme linked immunosorbent assay (Fig. 1). Sera from six patients (cases 1-6), all with disseminated disease, were positive when tested against all four antigens. Three patients (cases 7-9) were positive with three antigens, two (cases 10 and 11) with two antigens, and five (cases 12-16) with only one antigen. The diagnosis of invasive aspergillosis in the three seronegative patients rested solely on the histological identification of hyphae characteristic of Aspergillus after death: $A$ fumigatus was never cultured from sputum or other specimens either before or after death.

Ten patients (cases 1-10) had antibodies against both somatic and culture filtrate antigens from either commercial source. The first positive response to the Bencard somatic antigen occurred before that to the culture filtrate antigen in five patients (cases 1-4 and 10), all of whom developed disseminated aspergillosis. This response usually preceded clinical features suggestive of localised or disseminated infection (Fig. 2).

Raised IgG antibodies to one or other somatic antigen preparation were found in 10 of the 19 patients (cases 1-10), nine of whom developed disseminated infection. Antibodies to both somatic antigens were found in eight patients. All 16 seropositive patients had raised antibodies to one or both culture filtrate antigens. In five of the six patients (cases 11-16) with raised antibodies to only culture filtrate antigens the response was restricted to one or other of the two antigens. Although the magnitude of the response to culture filtrate antigens was often modest, it was associated with a more than four fold change in the antibody index (highest index/lowest index), whereas this four fold change was less common with the somatic antigens. Such large changes were not found in our patients without invasive aspergillosis who had undergone transplantation (data not shown).

Four of the 11 patients with invasive aspergillosis, from whom pretransplant sera were available, were seropositive before transplantation (cases 4, 8, 10, and 16). In two cases the earliest pretransplant antibody response was to Bencard somatic antigen, but in one case it was to Bencard culture filtrate and in the fourth it was to both Mercia Brocades antigens. Two examples are illustrated in Fig. 3. Death followed a precipitous fall in antibodies. All four patients in this selected series with antibodies to Aspergillus before transplantation died of disseminated infection. The mean survival time after transplantation in these four patients was $51 \cdot 5$ (SE 12.5) days and this compared with the mean survival time of 169 (35) days in the seven patients without antibody before transplantation. This difference was significant $(t=2.44 ; p<0.05)$.

In the 12 patients who died and were seropositive more than two weeks before death (cases 2-12 and 14) IgG antibodies to one or more Aspergillus antigens decreased and were no longer appreciably raised in the last serum sample obtained within two weeks of death (Fig. 1). The incidence and magnitude of this fall in antibodies differed among prep- 


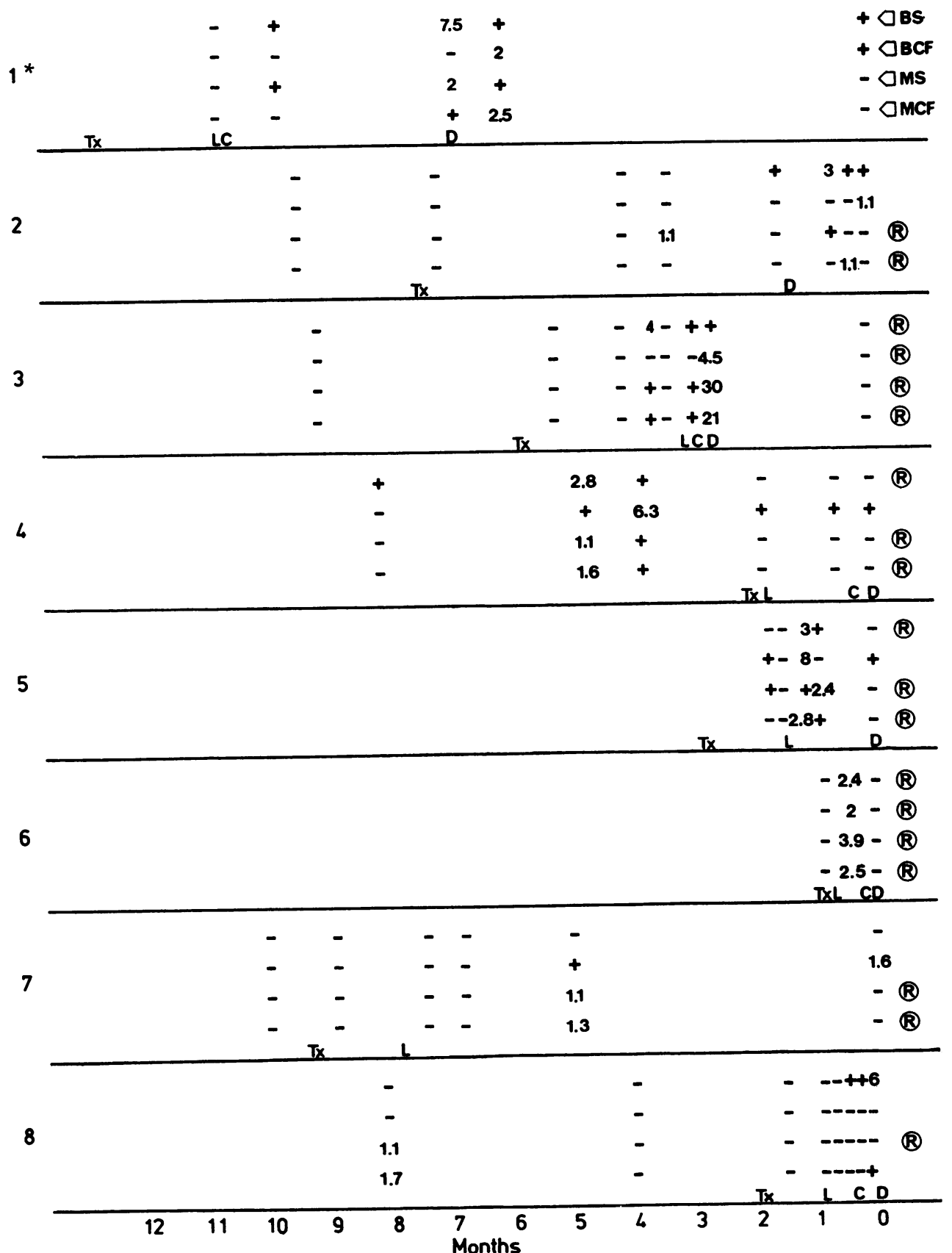

Patient $1\left(^{*}\right)$ is still alive, but for remaining 15 patients time 0 represents date

onths

$\mathbf{R}=$ incidence of reversion from seropositive to seronegative. Clinical details: $\mathrm{Tx}=$ transplant; $\mathrm{L}=$ earliest radiographic evidence consistent with localised aspergillosis; $C=A$ fumigatus cultured from sputum; $D=$ definitive evidence of disseminated aspergillosis (Aspergillus identified in biopsy or necropsy material by culture or morphology).

Fig. 1 Aspergillus IgG antibody response (+/-) to Bencard somatic (BS), Bencard culture filtrate (BCF), Mercia somatic (MS), and Mercia culture filtrate (MCF) antigens in serial serum samples from 16 patients with invasive aspergillosis. Peak antibody indices are represented numerically. 


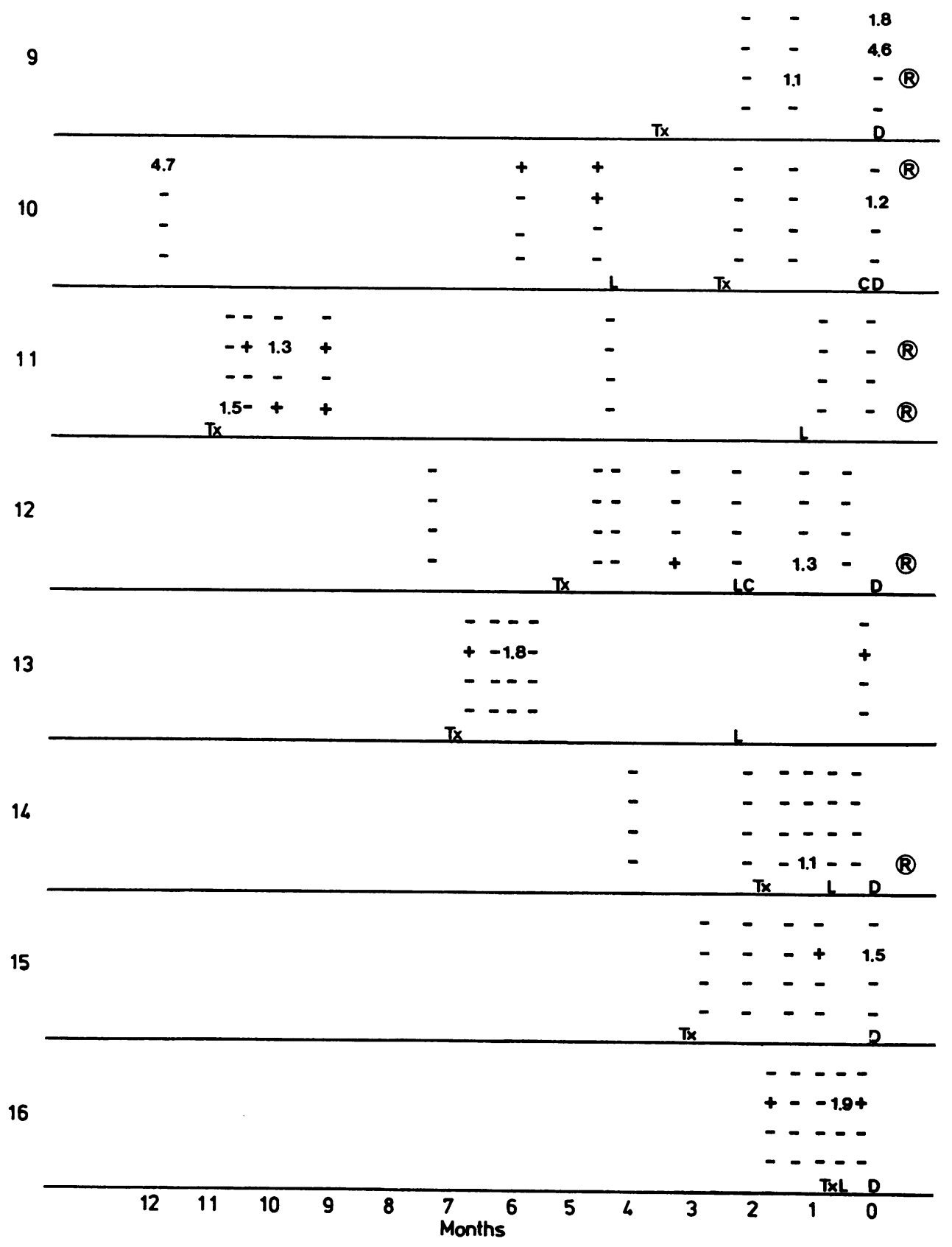


arations of antigens. Thus only three of the 12 patients who were seropositive against the Bencard culture filtrate antigen reverted to being seronegative around the time of death, whereas nine of the 10 patients who were seropositive against the Mercia Brocades culture filtrate antigen reverted. Of the eight patients who were seropositive against the Bencard somatic antigen, five reverted, and all eight patients who were seropositive against the Mercia Brocades somatic antigen also reverted.

\section{CARDIAC TRANSPLANT RECIPIENTS}

Of the 71 sera obtained from patients before cardiac transplantation, $10(14 \%)$ were positive against Bencard somatic, five (7\%) against Bencard culture filtrate, and seven (10\%) against both Mercia Brocades antigens. Two of the seropositive recipients of a transplant developed a further rise in antibodies after transplantation with cultural or biopsy evidence of aspergillosis. Of 128 sera from the 19 patients with invasive aspergillosis who had undergone renal or hepatic transplantation, 32 (25\%) were positive against Bencard somatic, 35 (28\%) against Bencard culture filtrate, 25 (20\%) against Mercia somatic, and $31(24 \%)$ against Mercia culture filtrate antigens.

\section{PATIENTS WITH LEUKAEMIA}

Of the 134 leukaemic patients, six (4.5\%) were seropositive against the Bencard somatic antigen, seven (5\%) against Bencard culture filtrate, four (3\%) against Mercia somatic, and eight (6\%) against Mercia culture filtrate antigens. The incidence of Aspergillus infection in this group has not yet been assessed.

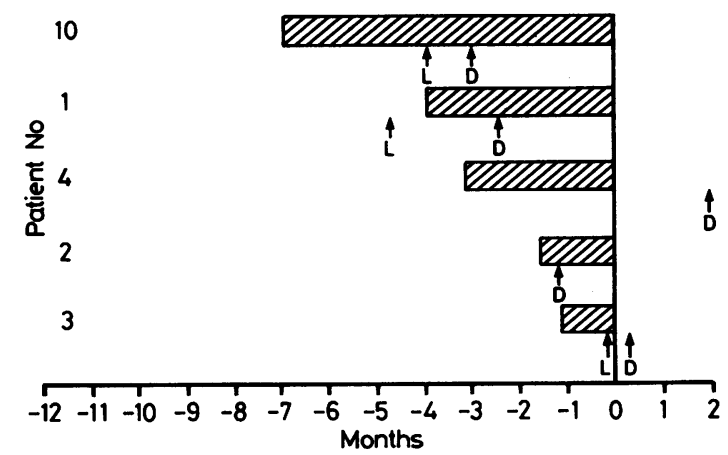

$L=$ earliest radiographic evidence consistent with localised aspergillosis; $D=$ earliest evidence of disseminated aspergillosis (clinical, cultural, or morphological).

Fig. 2 Time (in months) by which earliest significant Aspergillus $\lg G$ antibody response to Bencard somatic antigens preceded first significant response to Bencard culture filtrate antigens in five transplant recipients with invasive aspergillosis.

\section{Discussion}

All but three of the 19 patients with invasive aspergillosis had significantly raised serum IgG antibodies to one or more Aspergillus antigens at some time after transplantation. The three patients without antibodies were among those seven from whom no cultural evidence of infection with $\boldsymbol{A}$ fumigatus was obtained, a finding compatible with infection caused by other Aspergillus species. Histological material from the three seronegative patients, however, was not stained for Aspergillus by immunofluorescence, and their sera were not tested for antibodies to antigens derived from other filamentous fungi.

Four out of 11 renal and hepatic transplant recipients from whom pretransplant sera were available had high IgG antibody levels before the allograft. These four patients lived for a significantly shorter time after transplantation; all four patients had disseminated infection at necropsy. Infection may, therefore, have been established before transplantation. Depending on the antigen used, between five
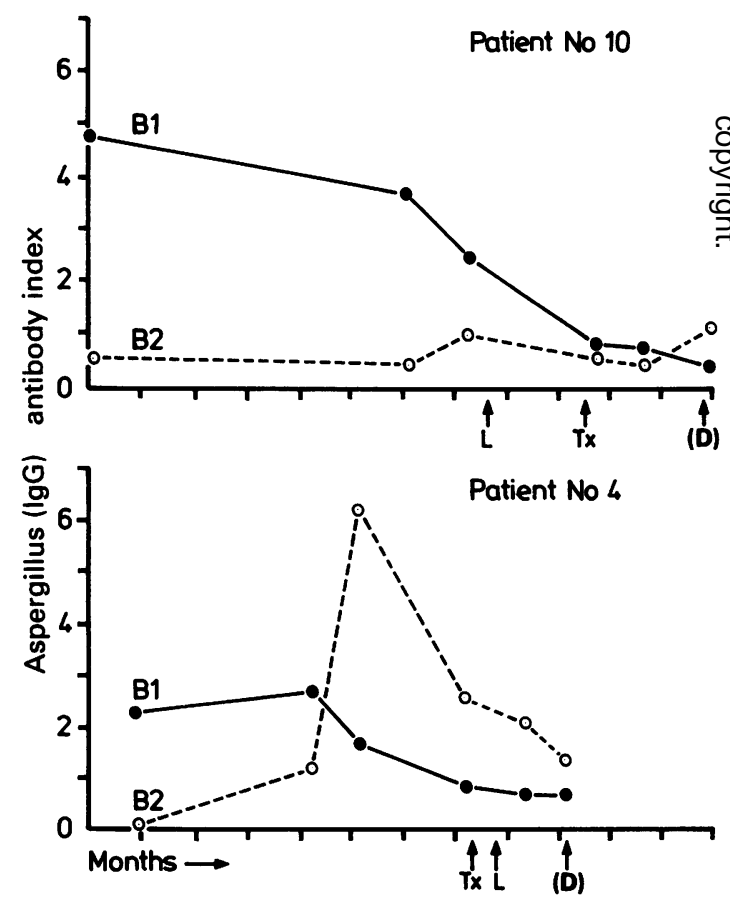

$\mathbf{L}=$ earliest radiographic evidence consistent with localised aspergillosis; $D$ earliest evidence of disseminated aspergillosis; $\mathbf{T x}=$ date of transplant; †date of death.

Fig. 3 Aspergillus IgG antibodies to Bencard somatic (B1) and culture filtrate (B2) antigens in multiple serum samples from two transplant recipients with invasive aspergillosis and raised antibodies before transplantation. 
and 10 of the 71 sera obtained preoperatively from cardiac transplant patients were positive in the enzyme linked immunosorbent assay, and two of these patients had cultural evidence of aspergillosis after transplantation. This preliminary observation, suggesting an increased risk of invasive infection in patients with preexisting antibodies, needs to be confirmed by prospectively examining serum from a larger group of transplant patients.

Between four and eight of the 134 sera from leukaemic patients were positive in the enzyme linked immunosorbent assay; again the incidence depended on the antigen used. Multiple sera are now being collected from these patients so that the prospective value of this test in immunocompromised patients can be more fully assessed. These background rates, showing a prevalence of seropositivity of $3-14 \%$ in similar immunocompromised patients suggest that the high incidence of antibody responses detected in patients with invasive aspergillosis will be valuable.

There was considerable variation in the timing and magnitude of individual responses to the different preparations of antigens. The somatic antigens appear to be most useful in early rather than late detection of disseminated aspergillosis, but culture filtrate antigens detect the highest proportion of positive antibody responses. The use of both somatic and culture filtrate antigens seems necessary at present for the reliable and early diagnosis of invasive aspergillosis by Aspergillus IgG enzyme linked immunosorbent assay.

By the time invasive aspergillosis is diagnosed antibodies may have fallen to within the normal range, even in cases of fulminant disseminated disease. Similar results have been reported by others." This fall in antibody levels may explain, in part, the poor results obtained with immunoprecipitation methods used in earlier investigations of single serum samples and the poor reputation of such tests when only late diagnoses are made. It also emphasises the necessity for prospectively collecting serum samples from immunocompromised patients for the assay of antibodies to Aspergillus.

Reports suggest that a successful outcome in treating invasive aspergillosis in immunocompromised patients depends on early diagnosis and whether
Aspergillus has disseminated from the lung. ${ }^{2}$ Techniques for detecting antibodies may permit earlier diagnosis, conceivably before the dissemination of Aspergillus to other organs. The impact of earlier diagnosis on the outcome of treatment with amphotericin B in chronically immunocompromised patients with invasive aspergillosis requires assessment.

We thank the Cancer Research Campaign for financial help.

\section{References}

' Rinaldi MG. Invasive aspergillosis. Rev Infect Dis 1983;5:1061-76.

${ }^{2}$ Stahel RA, Vogt P, Schuler G, Ruttner JR, Frick P, Oelz O. Systemic fungal infections in haematological malignancies: a growing problem. $J$ Infect 1982;5:269-75.

${ }^{3}$ Young RC, Bennett JE. Invasive aspergillosis: absence of detectable antibody response. Am Rev Respir Dis 1971;104:710-6.

${ }^{4}$ Coleman RM, Kaufman L. Use of the immunodiffusion test in the serodiagnosis of aspergillosis. Appl Microbiol 1972; 23:301-8.

${ }^{5}$ Gurwith MJ, Stinson EB, Remington JS. Aspergillus infection complicating cardiac transplantation. Arch Intern Med 1971;128:541-5.

- Schaefer JC, Yu B, Armstrong D. An Aspergillus immunodiffusion test in the early diagnosis of aspergillosis in adult leukaemia patients. Am Rev Respir Dis 1976;113:325-9.

7 Gold JWM, Fisher B, Yu B, Chein N, Armstrong D. Diagnosis of invasive aspergillosis by passive hemagglutination assay of antibody. J Infect Dis 1980;142:87-94.

${ }^{8}$ Marier R, Smith W, Jansen M, Andriole VT. A solid-phase radioimmunoassay for the measurement of antibody to Aspergillus in invasive aspergillosis. J Infect Dis 1979;140:771-9.

${ }^{4}$ Mishra SK, Falkenberg S, Masihi KN. Efficacy of enzyme-linked immunosorbent assay in serodiagnosis of aspergillosis. J Clin Microbiol 1983; 17: 708-10.

${ }^{10}$ Milford-Ward A. In: Thompson RA, ed. Immunoprecipitation in the evaluation of the proteins in plasma and body fluids. Techniques in clinical immunology. Oxford: Blackwell Scientific Publications, 1977:1-24.

" Holmberg K, Berdischewsky M, Young LS. Serologic immunodiagnosis of invasive aspergillosis. J Infect Dis 1980;141:656-64.

Requests for reprints to: Dr AK Trull, Clinical Microbiology and Public Health Laboratories, 6th floor Laboratories Block, New Addenbrooke's Hospital, Hill's Road, Cambridge CB2 2QQ England. 